\title{
Tumor Angiogenesis
}

National Cancer Institute

\section{Source}

National Cancer Institute. Tumor Angiogenesis. NCI Thesaurus. Code C19361.

Proliferation of blood vessels in a tumor. 